\title{
Androgenic control of polyamine concentrations in rat epididymis
}

\author{
M. A. de las Heras ${ }^{1}$, S. I. Gonzalez ${ }^{1}$ and R. S. Calandra ${ }^{1,2}$ \\ ${ }^{1}$ Laboratorio de Esteroides, Instituto de Biología y Medicina Experimental, Vuelta de Obligado \\ 2490, 1428, Buenos Aires; and ${ }^{2}$ Cátedra de Endocrinología, Facultad de Ciencias Exactas, UNLP, \\ La Plata, Argentina
}

\begin{abstract}
Summary. Unilateral orchidectomy resulted in a significant decrease in tissue content of putrescine and polyamines. However, no differences were detected when the results were expressed in terms of $\mathrm{ng} \mathrm{g}^{-1}$ tissue. At $48 \mathrm{~h}$ after bilateral orchidectomy, a significant decrease in putrescine content was observed, but spermidine and spermine content were unaffected. The observed decrease in putrescine was prevented by treatment with testosterone propionate, but neither spermidine nor spermine were affected. Bilateral orchidectomy resulted in a significant decrease in the tissue content of putrescine, spermidine and spermine after 7 days. Treatment with testosterone propionate increased the content of putrescine, spermidine and spermine in the epididymis by about $200 \%$, $92 \%$ and $34 \%$, respectively. When results were expressed as $n m o l \mathrm{~g}^{-1}$, a significant decrease after castration in putrescine and spermidine, but not in spermine, was observed. Treatment with testosterone propionate restored putrescine concentration, but had no effect on spermidine and spermine concentrations. In castrated rats treated with testosterone propionate, the anti-androgen flutamide abolished the effect of the androgen on putrescine and spermidine content, but there was no effect on spermine.

Acetylputrescine was not detected in the epididymis, while acetylpolyamines were detected at much lower concentrations than polyamines. After bilateral orchidectomy there was a decrease in the tissue content of all acetylpolyamines and an increase in their tissue concentration. The effect of castration on acetylpolyamine content was reversed by testosterone propionate treatment. We conclude that an active synthesis of polyamines occurs in the rat epididymis, and that this process depends upon the androgen environment. Regulation of ornithine decarboxylase activity appears to be the main step that is controlled by androgens.
\end{abstract}

Keywords: flutamide; putrescine; testosterone; spermidine; spermine; rat

\section{Introduction}

Seminal plasma from most species contains high concentrations (millimolar) of the polyamines, spermidine and spermine. In contrast, bovine seminal plasma contains only trace amounts of these polyamines (Mann, 1964), probably because of the low prostatic activity of bulls. The prostate gland is the main organ that secretes polyamines into the semen (Piik et al., 1977), and ornithine decarboxylase (ODC) activity, the rate-limiting enzyme in polyamine biosynthesis, is particularly high in the ventral lobe of the prostate gland (Fjösne et al., 1988). However, this fact does not rule out the possibility that these compounds are synthesized and secreted in other organs of the male genital tract such as the seminal vesicles (Piik et al., 1977; Gonzalez et al., 1991), for the maintenance of their specific functions. 
The presence of polyamines seems to be physiologically important in the initiation of spermatogenesis and changes in both ODC and $S$-adenosyl-L-methionine decarboxylase (SAMDC) in the testis correlates with the development of the cells in the seminiferous tubules during the first wave of spermatogenesis (Shubhada et al., 1989), since cultures of Sertoli cells secrete polyamines under follicle-stimulating hormone (FSH) stimulation, through ODC activation (Francis et al., 1981; Swift \& Dias, 1987). This action is likely to be important for spermatogenesis to proceed normally (MacIndoe \& Turkington, 1973). However, several effects of polyamines have been described on mature spermatozoa (Pulkinen et al., 1975; Shah et al., 1975; Shah \& Sheth, 1978; Casillas et al., 1980). In contrast, no attention has been paid to the contribution of polyamines to the process of sperm maturation in the epididymis. We have detected ODC activity in rat epididymis and demonstrated that this enzyme is strictly androgen dependent (de las Heras \& Calandra, 1987; de las Heras et al., 1988). We have also observed epididymal SAMDC activity, necessary for the synthesis of spermidine and spermine; and its androgenic control (de las Heras \& Calandra, 1991). Using similar experimental models, by altering the androgen environment of the epididymis, we investigated whether polyamine content is affected by changes in ODC and SAMDC activities.

\section{Materials and Methods}

\section{Animals and treatments}

Adult male Sprague-Dawley rats were maintained in an air-conditioned room $\left(22^{\circ} \mathrm{C}\right)$ with light on from 7.00 to $19.00 \mathrm{~h}$, and received laboratory chow and water ad libitum.

Unilateral and bilateral orchidectomies were performed by the scrotal route under ether anaesthesia. Testosterone propionate $\left(50-500 \mu \mathrm{g}\right.$ in corn oil) was injected s.c. Flutamide $\left(1\right.$ or $\left.5 \mathrm{mg} \mathrm{day}^{-1}\right)$ was injected s.c. as a suspension in $0.9 \% \mathrm{NaCl}$ solution containing $1 \%$ gelatin, twice a day for 7 days. In all cases, treatments began $24 \mathrm{~h}$ after orchidectomy. The animals were killed by decapitation on the morning of day 8 . Epididymides were dissected free from fat tissue and kept at $-20^{\circ} \mathrm{C}$ until assayed for polyamine.

\section{Chemicals}

All reagents (Sigma Chemical Co., St Louis MO, USA) and solvents (Merck Darmstadt, Germany) were of analytical grade. Testosterone propionate was a gift from Laboratorios Gador (Buenos Aires, Argentina). The anti-androgen flutamide was kindly provided by Schering Canada (courtesy of F. Labrie).

\section{Measurement of polyamine}

Assessment of putrescine and the polyamines, spermidine and spermine, was carried out by the method described by Seiler (1983), with slight modifications and adapted for epididymal tissue. Epididymides were thawed, cut and homogenized in $0.2 \mathrm{~mol}$ perchloric acid $\mathrm{l}^{-1}$, at $5 \mathrm{ml} \mathrm{g}^{-1}$ tissue. After centrifugation at $20000 \mathrm{~g}$ for $30 \mathrm{~min}$, aliquots $(100 \mu \mathrm{l})$ from supernatants were rendered alkaline with $100 \mu \mathrm{l}$ of saturated sodium carbonate solution, and added to

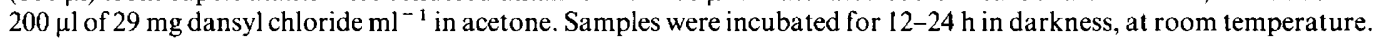
Excess dansyl was eliminated by the addition of $500 \mu \mathrm{l}$ of $100 \mathrm{mg}$ proline $\mathrm{ml}^{-1}$ in water, with further incubation for $1 \mathrm{~h}$. Samples were evaporated to dryness under nitrogen at $45^{\circ} \mathrm{C}$ and resuspended in water $(200 \mu \mathrm{l})$. Dansyl derivatives of putrescine, spermidine and spermine were extracted with $200 \mu \mathrm{l}$ of toluene. After phase separation by centrifugation and freezing of the aqueous phase, $50 \mu \mathrm{l}$ aliquots of the extracts were spotted on silica-gel plates (Merck, $250 \mu \mathrm{l}$ thickness), previously activated at $110^{\circ} \mathrm{C}$ for $1 \mathrm{~h}$. Standards containing $10 \mathrm{nmol}$ of putrescine, spermidine and spermine were treated in the same way as the sample, and volumes containing $0 \cdot 25,0 \cdot 5,1 \cdot 0$ and $2.0 \mathrm{nmol}$ were spotted on the same plates. Two runs were carried out using cyclohexane:ethyl acetate $(1: 1, \mathrm{v} / \mathrm{v})$, followed by a third run with cyclohexane:ethyl acetate $(3: 2, v / v)$, in the dark. The plates were then sprayed with triethanolamine:isopropanol $(1: 4$, $\mathrm{v} / \mathrm{v})$, to stabilize the fluorescence of dansyl derivatives. The bands corresponding to didansylputrescine, tridansylspermidine and tetradansylspermine were identified using an ultraviolet light source ( $366 \mathrm{~nm}$ wavelength) and eluted with $1 \mathrm{ml}$ of benzene:triethylamine $(95: 5, \mathrm{v} / \mathrm{v})$. Fluorescence of the resulting solutions was measured in an Aminco-Bowman spectrofluorometer, at $350 \mathrm{~nm}$ and $490 \mathrm{~nm}$ wavelength for excitation and emission, respectively. Fluorescence of dansyl derivatives of putrescine, spermidine and spermine was linear to the volume of sample. Values of $R_{\mathrm{F}}$ were $0.62,0.53$ and 0.45 for dansyl derivatives of putrescine, spermidine and spermine, respectively.

The sensitivity of the polyamine assay was $0.125 \mathrm{nmol}$ in $500 \mu$ l. The intra-assay and interassay coefficients of variation were $\pm 3-5 \%$ for both parameters. The recovery of polyamines throughout the whole procedure was $>90 \%$. Results were expressed as $\mathrm{nmol}^{-1}$ tissue or nmol per organ. 


\section{Assessment of acetylputrescine and acetylpolyamines}

The method used for assessment of acetylated polyamines, analogous to that described for the assessment of putrescine and polyamines, was adequate for its application to the epididymal tissue, although the amounts of these compounds were near the detection limit $(0.125 \mathrm{nmol})$.

Analysis of acetylputrescine and acetylpolyamines was performed as described for putrescine and polyamines, with the following modifications: (i) acetylputrescine, $N^{1}$-acetylspermidine, $N^{8}$-acetylspermidine and $N^{1}$-acetylspermine were used as standards; (ii) tissues were homogenized in a minimal volume of perchloric acid ( $400 \mu \mathrm{l}$ for epididymides from intact rats and $200 \mu \mathrm{l}$ for those from castrated rats); (iii) interference from putrescine and polyamines was avoided by performing two runs using ethyl acetate, and acetylated derivatives were separated by a third run in chloroform:carbon tetrachloride:methanol $(14: 6: 1, \mathrm{v} / \mathrm{v} / \mathrm{v})$; (iv) the bands corresponding to each compound were eluted in $500 \mu \mathrm{l}$ benzene:triethylamine $(95: 5, \mathrm{v} / \mathrm{v})$.

Values of $R_{\mathrm{F}}$ were $0.37,0.53,0.58$ and 0.68 for acetylputrescine, $N^{1}$-acytylspermidine, $N^{8}$-acetylspermidine and acetylspermine, respectively.

\section{Statistical analysis}

Differences between groups were analysed by ANOva and Duncan's multiple range test (Li, 1964). $P \geqslant 0 \cdot 05$ was considered not significant.

\section{Results}

\section{Effect of unilateral orchidectomy}

Unilateral orchidectomy resulted in a significant decrease in the tissue content (expressed as nmol per organ) of putrescine, spermidine and spermine. However, no differences were detected when results were expressed in terms of tissue concentration, i.e. as $\mathrm{nmol} \mathrm{g}^{-1}$ (Figs 1 and 2).

(a)

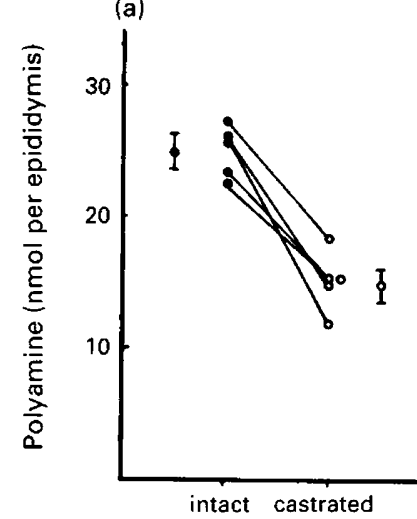

(b)

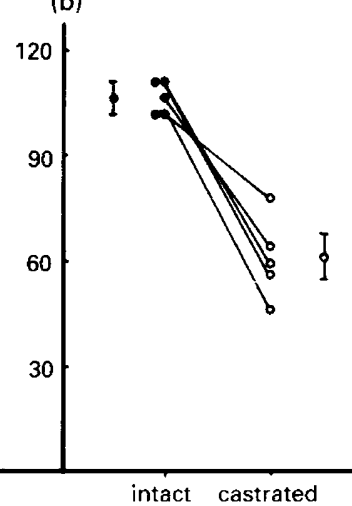

(c)

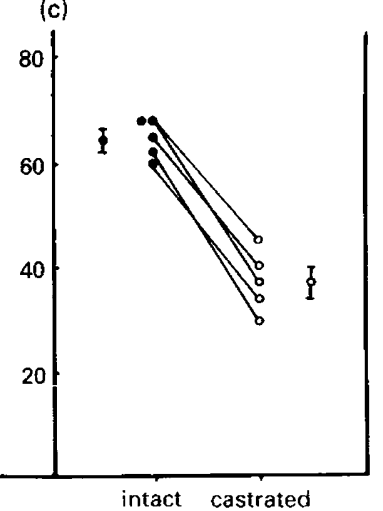

Fig. 1. Content of (a) putrescine, (b) spermidine and (c) spermine in epididymides from unilaterally orchidectomized rats. Individual values for each pair of epididymides are represented, together with mean $\pm \operatorname{SEM}(\bigcirc)$ normal (intact) side; $(O)$ castrated side. Differences are significant $(P<0.01)$ in all cases.

\section{Effect of bilateral orchidectomy and androgen replacement}

In a first series of experiments, the effect of bilateral orchidectomy was studied $48 \mathrm{~h}$ after castration, before atrophy of the organ which occurs after several days. Rats were orchidectomized and epididymides dissected 24 and $48 \mathrm{~h}$ later. No differences in organ weight were observed at these intervals. Under these conditions, a significant decrease $(P<0.05)$ in putrescrine content was observed at $48 \mathrm{~h}$, whereas spermidine and spermine content remained unaffected (Fig. 3). The observed decrease in putrescine was prevented by testosterone propionate treatment, but neither spermidine nor spermine were affected (Fig. 4). 
(a)

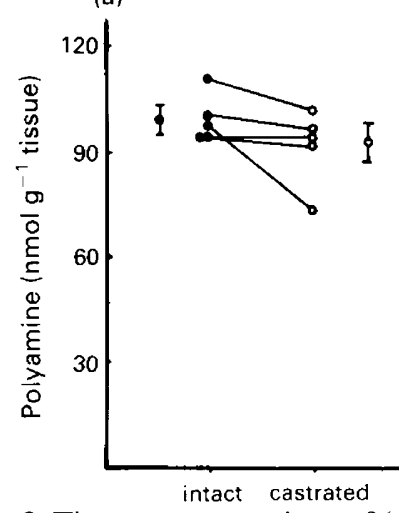

(b)

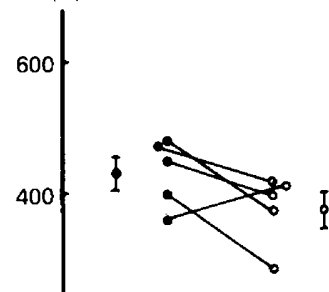

(c)

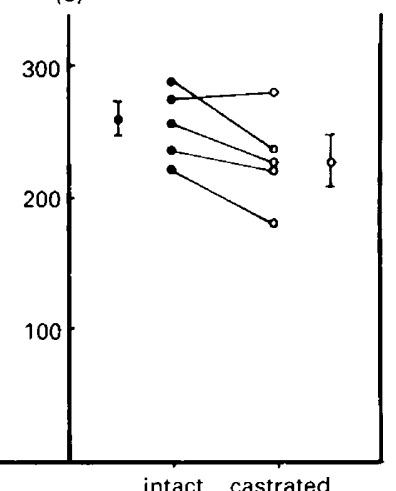

Fig. 2. Tissue concentrations of (a) putrescine, (b) spermidine and (c) spermine in epididymides from unilaterally orchidectomized rats. Individual values for each pair of epididymides are represented, together with mean \pm SEM. (O) normal (intact) side; $(O)$ castrated side. Differences are not significant $(P<0.05)$ in any case.

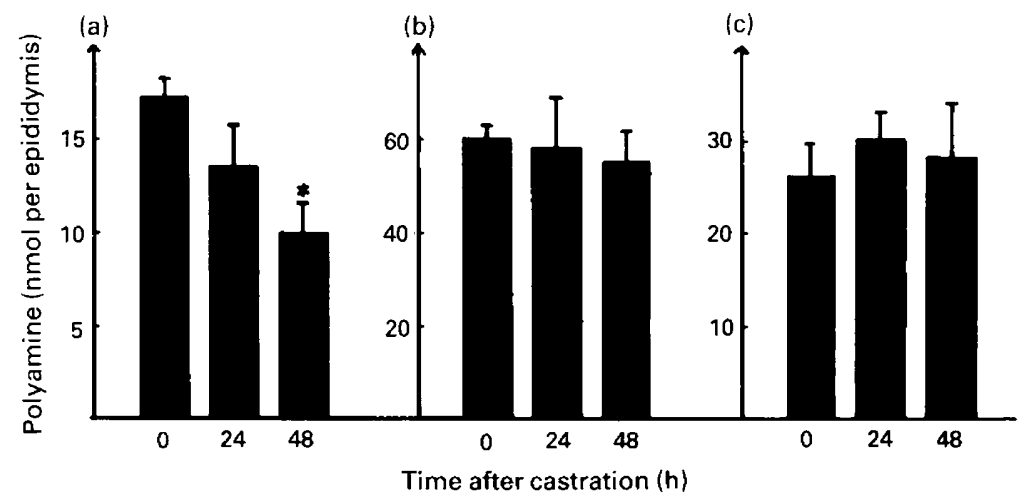

Fig. 3. Content of (a) putrescine, (b) spermidine and (c) spermine in rat epididymides 24 and $48 \mathrm{~h}$ after castration. Values represent mean \pm SEM for five individual determinations. ${ }^{*} P<0.05$ with respect to values at $0 \mathrm{~h}$.
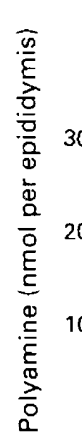

(a)

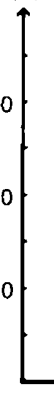

(b)

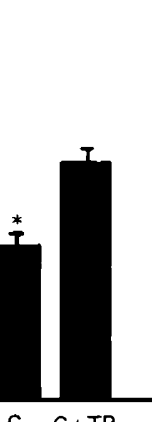

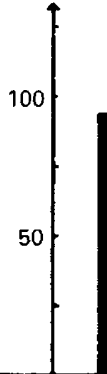
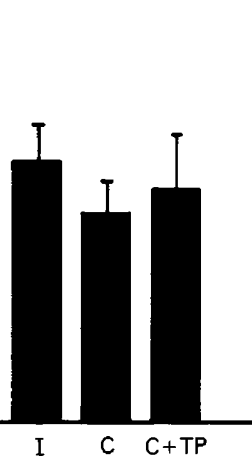

(c)

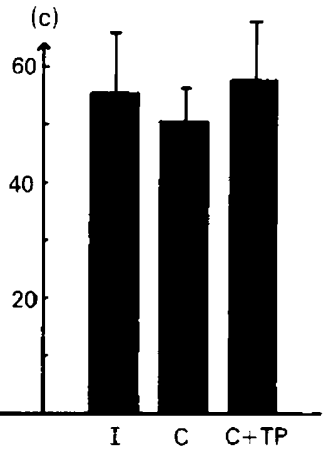

Fig. 4. Effect of testosterone propionate $\left(500 \mu \mathrm{g} \mathrm{day}^{-1}\right)$ on epididymal content of (a) putrescine, (b) spermidine and (c) spermine in castrated rats. Treatments began immediately after castration. Values represent mean \pm SEM for five individual determinations. I: intact; C: castrated; TP: testosterone propionate. ${ }^{*} P<0.05$ with respect to intact animals. 
In a second series of experiments, rats were orchidectomized and epididymal polyamines measured after 7 days. In this case, a $62 \%$ decrease in epididymal weight was observed, and this loss was partially prevented by testosterone propionate $\left(50 \mu \mathrm{g} \mathrm{day}^{-1}\right)$ treatment. The weight loss was accompanied by a significant decrease in the tissue content of putrescine, spermidine and spermine (Table 1). Treatment with testosterone propionate increased the epididymal content of these compounds in orchidectomized animals. Putrescine content increased about $200 \%$ with respect to nontreated castrated animals, whereas amounts of spermidine and spermine increased $92 \%$ and $34 \%$, respectively (Table 1). When results were expressed as $\mathrm{nmol}^{-1}$, a significant decrease after castration was observed for putrescine and spermidine, but there was no change in amount of spermine. Treatment with testosterone propionate restored putrescine concentration, but had no effect on spermidine and spermine concentrations.

Table 1. Concentration and content of putrescine, spermidine and spermine in epididymides from intact, castrated, and castrated rats treated with testosterone propionate $\left(0.05 \mathrm{mg} \mathrm{day}^{-1}\right)$

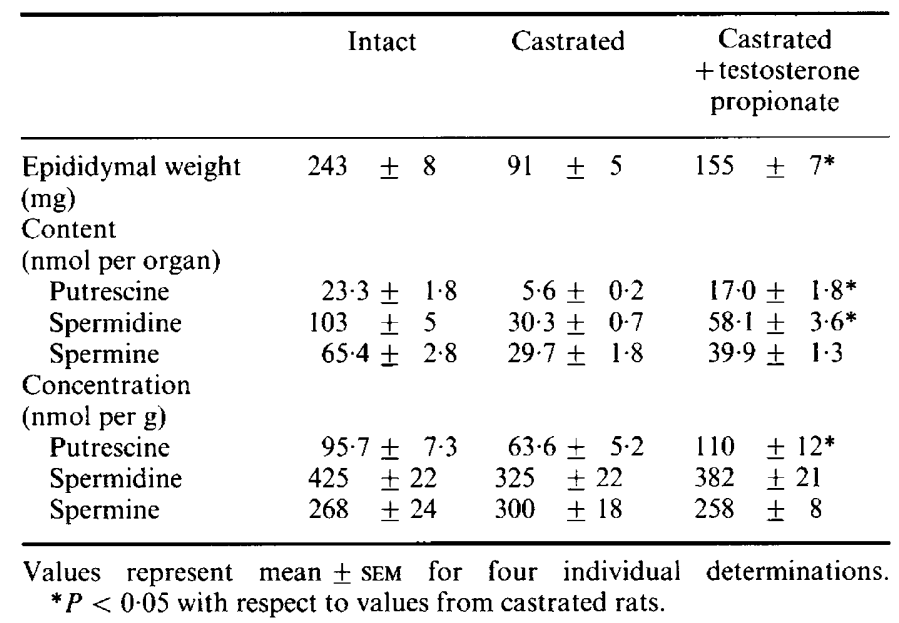

\section{Effect of antiandrogen flutamide}

Flutamide, at doses of 1 and $5 \mathrm{mg} \mathrm{day}^{-1}$ for 7 days, did not affect the content or concentration of putrescine or polyamines in the epididymis. The effect of flutamide in the presence of constant androgen concentrations was evaluated in rats $24 \mathrm{~h}$ after castration by injecting them with testosterone propionate $\left(50 \mu \mathrm{g} \mathrm{day}^{-1}\right)$ plus flutamide $\left(1 \mathrm{mg}\right.$ day $\left.{ }^{-1}\right)$. The antiandrogen abolished the effect of testosterone propionate on putrescine and spermidine content, but there was no effect on spermine (Table 2).

\section{Presence of acetylated polyamines in the epididymis: effect of orchidectomy and androgen replacement}

Acetylputrescine was not detected in either intact, castrated or testosterone propionate-treated rats (Table 3). However, acetylpolyamines were detected at much lower concentrations than polyamines. Bilateral orchidectomy provoked a decrease in the tissue content of all acetylpolyamines. However, the concentration of these compounds in tissues showed a different profile, as they increased after castration. 
Table 2. Effect of flutamide on polyamine content in epididymis from intact rats and castrated rats treated with $50 \mu \mathrm{g}$ testosterone propionate day $^{-1}$

\begin{tabular}{|c|c|c|c|}
\hline Treatment & $\begin{array}{c}\text { Putrescine } \\
\text { (nmol per organ) }\end{array}$ & $\begin{array}{c}\text { Spermidine } \\
\text { (nmol per organ) }\end{array}$ & $\begin{array}{c}\text { Spermine } \\
\text { (nmol per organ) }\end{array}$ \\
\hline \multicolumn{4}{|l|}{ Intact } \\
\hline Vehicle & $23 \cdot 3 \pm 1 \cdot 8$ & $103 \cdot 0 \pm 6 \cdot 0$ & $65 \cdot 4 \pm 2 \cdot 8$ \\
\hline $\begin{array}{l}\text { Flutamide } \\
\left(1 \mathrm{mg} \mathrm{day}^{-1}\right)\end{array}$ & $22 \cdot 5 \pm 0.8$ & $97 \cdot 1 \pm 0.4$ & $64 \cdot 6 \pm 3 \cdot 1$ \\
\hline $\begin{array}{l}\text { Flutamide } \\
\left(5 \mathrm{mg} \mathrm{day}^{-1}\right)\end{array}$ & $19 \cdot 4 \pm 1 \cdot 0$ & $83 \cdot 3 \pm 6 \cdot 4$ & $56 \cdot 7 \pm 3 \cdot 5$ \\
\hline \multicolumn{4}{|l|}{ Castrated } \\
\hline Vehicle & $5 \cdot 6 \pm 0.2$ & $30 \cdot 3 \pm 0 \cdot 6$ & $29.7 \pm 1.8$ \\
\hline $\begin{array}{l}\text { Testosterone propionate } \\
\left(50 \mu \mathrm{g} \mathrm{day}^{-1}\right)\end{array}$ & $17 \cdot 0 \pm 1 \cdot 8$ & $58 \cdot 1 \pm 6 \cdot 2$ & $39 \cdot 9 \pm 1 \cdot 3$ \\
\hline $\begin{array}{l}\text { Testosterone propionate } \\
\left(50 \mu \mathrm{g} \mathrm{day}^{-1}\right)\end{array}$ & & & \\
\hline $\begin{array}{l}\text { + Flutamide } \\
\left(1 \mathrm{mg} \mathrm{day}^{-1}\right)\end{array}$ & $7 \cdot 4 \pm 0 \cdot 3^{*}$ & $39 \cdot 4 \pm 2 \cdot 8$ & $34 \cdot 6 \pm 1 \cdot 2$ \\
\hline
\end{tabular}

Values represent mean \pm SEM for four individual determinations. ${ }^{*} P<0.05$ with respect to androgen-treated castrated rats.

The effect of castration on acetylpolyamine content was reversed by testosterone propionate. When expressed in terms of tissue concentration, the action of testosterone propionate on $N^{8}$ acetylspermidine was evident.

\section{Discussion}

The aim of the present study was to analyse the extent by which alteration in the activities of the limiting enzymes of polyamine biosynthesis lead to changes in the content and concentration of these compounds in the epididymis.

The epididymis is adjacent to the testis, and therefore a direct comparison between intact and castrated animals is not possible, since castration results in both an inhibition of androgenic stimulus and suppression of the contribution of testicular fluid, which may contain considerable amounts of polyamines. This seems to be the case, as unilateral orchidectomy, which prevents the testicular fluid from reaching the epididymis without a significant involution of the organ, results in a decrease in the content of putrescine and polyamines, but there is no effect on their tissue concentrations. This fact suggests that an important fraction of putrescine and polyamines present in the epididymis comes from the testis. The effect of androgens should therefore be assessed using unilaterally castrated, bilaterally castrated or efferent-duct-ligated animals as controls. Our results show that castration rapidly results in a decrease in the amount of putrescine without changes in the amounts of spermidine or spermine. Taking into account the observation that ODC activity cannot be detected $24 \mathrm{~h}$ after castration (de las Heras \& Calandra, 1987), and that the decrease in putrescine content is prevented by testosterone, we suggest that at least an important fraction of the putrescine measured in the epididymis is synthesized within the epididymis. The fact that $48 \mathrm{~h}$ after castration the amounts of spermidine and spermine in the epididymis have not been affected suggests a lower turnover of these compounds with respect to their precursor.

Moreover, the observed decrease in putrescine without changes in the sum of spermidine plus spermine suggests the conversion of this diamine into other metabolite(s). A possible explanation is that putrescine is converted to acetylated derivatives but, the low sensitivity of the method for the 
Table 3. Content and concentration of acetylputrescine and acetylpolyamines in epididymides from intact and castrated rats treated with $500 \mu \mathrm{g}$ testosterone propionate every second day for 7 days

\begin{tabular}{|c|c|c|c|}
\hline \multirow{3}{*}{$\begin{array}{l}\text { Epididymal weight }(\mathrm{mg}) \\
\text { Content } \\
\text { (nmol per organ) }\end{array}$} & Intact & Castrated & $\begin{array}{c}\text { Castrated } \\
+ \text { testosterone } \\
\text { propionate }\end{array}$ \\
\hline & $205 \cdot 0 \pm 14 \cdot 0$ & $55.0 \pm 3.0$ & $147.0 \pm 6.0^{* *}$ \\
\hline & & & \\
\hline Acetylputrescine & ND & ND & ND \\
\hline $\mathrm{N}^{1}$-Acetylspermidine & $2.29 \pm 0.14$ & $1 \cdot 10 \pm 0 \cdot 02$ & $2 \cdot 60 \pm 0 \cdot 24^{* *}$ \\
\hline $\mathrm{N}^{8}$-Acetylspermidine & $2.15 \pm 0.08$ & $0.94 \pm 0.02$ & $2.00 \pm 0.05^{* *}$ \\
\hline Acetylspermine & $2.75 \pm 0.12$ & $1.14 \pm 0.02$ & $2.49 \pm 0.11^{* *}$ \\
\hline \multicolumn{4}{|l|}{$\begin{array}{l}\text { Concentration } \\
\left(\mathrm{nmol} \mathrm{g}^{-1}\right)\end{array}$} \\
\hline Acetylputrescine & ND & ND & ND \\
\hline $\mathrm{N}^{1}$-Acetylspermidine & $11 \cdot 20 \pm 0.35$ & $18.70 \pm 1.06$ & $17.80 \pm 1.48$ \\
\hline $\mathrm{N}^{8}$-Acetylspermidine & $10.60 \pm 0.51$ & $16.80 \pm 0.98$ & $13.70 \pm 0.71^{*}$ \\
\hline Acetylspermine & $13.50 \pm 0.66$ & $21.00 \pm 1.36$ & $17 \cdot 00 \pm 0.94^{*}$ \\
\hline
\end{tabular}

assessment of acetylputrescine used in this study did not allow us to test the possibility of a stimulation of putrescine acetylation under these conditions. A second possibility would be that putrescine is oxidised to compounds such as gamma-aminobutyric acid (GABA). Results from our laboratory (Ritta \& Calandra, 1986) show that GABA is present in the rat testis, and preliminary studies suggests that it could be synthesized in the epididymis.

A marked decrease in the content of putrescine and polyamines 7 days after castration was observed in our experiments. This effect is obviously due to both the suppression of testicular contribution and the atrophy of the epididymis. The effectiveness of testosterone in restoring amounts of putrescrine and polyamine followed the order putrescine $>$ spermidine $>$ spermine. Moreover, with the exception of the slight decrease in spermidine after castration, the tissue concentration of polyamines was unaffected by castration or androgen replacement. The antiandrogenic action of flutamide was directly related to the androgenic action of testosterone. These facts allow us to suggest that (i) the main step controlling polyamine biosynthesis is at the ODC level, as the direct product of its action, i.e. putrescine, is most affected by the androgen environment; and (ii) the epididymis seems to possess mechanisms for maintaining the tissue concentration of spermidine and spermine essentially constant. This could be achieved, for instance, by means of an androgendependent inhibition of polyamine catabolism, or by the uptake of circulating polyamines. In other models, polyamine uptake is stimulated when ODC is inhibited by $\alpha$-difluoromethylornithine (Kadmon et al., 1982).

Acetylation of polyamines is involved in their interconversion and catabolism. In this study, we determined the amount of acetylputrescine and acetylpolyamines in the epididymis, as well as their androgen control. The tissue concentration of acetylpolyamines was increased after castration (Table 3). This fact is in accordance with the notion that acetylpolyamines can be detected when polyamine breakdown is increased (Bolkenius \& Seiler, 1981). The production of acetylpolyamines is expected to occur via polyamines. In our experiments, the increase in acetylpolyamines was about $20 \mathrm{nmol} \mathrm{g}^{-1}$, and hence a similar decrease in polyamines, which are present at much higher concentrations, could not be detected. Acetylation does not therefore seem to be involved in the disappearance of polyamines from the epididymis of castrated rats, at least not before 7 days after castration. This is in accordance with the notion that certain mechanism(s) would prevent polyamine loss from the epididymis after androgen withdrawal. 
We conclude that polyamines are synthesized in the rat epididymis and that this process is under the control of androgens. Further studies are necessary to elucidate the involvement of polyamines of epididymal origin in sperm maturation.

We thank D. E. Bas for skilful technical assistance and D. B. Destéfano for typing the manuscript. This work was supported by Consejo Nacional de Investigaciones Científicas y Técnicas (CONICET) de la República Argentina.

\section{References}

Bolkenius, F.N. \& Seiler, N. (1981) Acetylderivatives as intermediates in polyamine catabolism. International Journal of Biochemistry 13, 287-292.

Casillas, E.R., Elder, C.M. \& Hoskins, D.D. (1980) Adenylate cyclase activity of bovine spermatozoa during maturation in the epididymis and the activation of sperm particulate adenylate cyclase by ATP and polyamines. Journal of Reproduction and Fertility $59,297-302$.

de las Heras, M.A. \& Calandra, R.S. (1987) Androgen dependence of ornithine decarboxylase in the rat epididymis. Journal of Reproduction and Fertility 79, 9-14.

de las Heras, M.A. \& Calandra, R.S. (1991) S-AdenosylL-Methionine decarboxylase activity in the rat epididymis: ontogenic and androgenic control. Journal of Andrology 12, 209-213.

de las Heras, M.A., Suescun, M.O. \& Calandra, R.S. (1988) Ornithine decarboxylase activity as a marker of androgen and antiandrogen action in the rat epididymis. Journal of Reproduction and Fertility 83, 177-183.

Fjösne, H.E., Strand, H., Ostensen, M.A. \& Sunde, A. (1988) Ornithine decarboxylase and S-adenosylmethionine decarboxylase activity in the accessory sex organs of intact, castrated and androgenstimulated castrated rats. The Prostate 12, 309-320.

Francis, G.L., Triche, T.J., Brown, H.C. \& Bercu, B.B. (1981). In vitro gonadotropin stimulation of bovine Sertoli cell ornithine decarboxylase activity. Journal of Andrology 2, 312-318.

Gonzalez, S.I., Chandrashekar, V., Shire, J.G.M., Lüthy, I.A., Bartke, A. \& Calandra, R.S. (1991) Effects of hyperprolactinemia on ornithine decarboxylase activity and polyamine levels in seminal vesicles of genetically prolactin-deficient adult dwarf mice. Biology of Reproduction 44, 321-326.

Kadmon, D., Heston, W.D.W., Lazon, D.W. \& Fair, W.R. (1982) Difluoromethylornithine enhancement of putrescrine uptake into prostate: concise communication. Journal of Nuclear Medicine 23, 988-1002.
Li, C.C. (1964) Introduction to Experimental Statistics. McGraw-Hill, New York.

MacIndoe, J.H. \& Turkington, R.W. (1973) Hormonal regulation of spermidine formation during spermatogenesis in the rat. Endocrinology 92, 595-602.

Mann, T. (1964) The Biochemistry of Semen and of the Male Reproductive Tract. John Wiley and Sons, New York.

Piik, K., Rajamaki, P., Guha, S.K. \& Jänne, J. (1977) Regulation of L-ornithine decarboxylase and Sadenosyl-L-methionine decarboxylase in rat ventral prostate. Biochemical Journal 168, 379-385.

Pulkinen, P., Sinervirta, R. \& Jänne, J. (1975) Modifications of the metabolism of rat epididymal spermatozoa by spermine. Biochemical and Biophysical Research Communications 67, 714-722.

Ritta, M.N. \& Calandra, R.S. (1986) Occurrence of GABA in rat testis and its effect on androgen production. In GABA and Endocrine Function, Vol. 42, pp. 291-296. Eds G. Racagni and A. O. Donoso. Raven Press, New York.

Seiler, N. (1983) Thin-layer chromatography and thin-layer electrophoresis by polyamines and their derivatives. Methods in Enzymology 94, 3-9.

Shah, G.V. \& Sheth, A.R. (1978) Inhibition of phosphodiesterase activity of human spermatozoa by spermine. Experientia 34, 980-981.

Shah, G.V., Sheth, A.R., Mugatwala, P.P. \& Rao, S.S. (1975) Effect of spermine on adenyl cyclase activity of spermatozoa. Experientia 31, 631-632.

Shubhada, S., Lin, S.N., Qian, Z.Y., Steinberger, A. \& Tsai, Y.H. (1989) Polyamine profiles in rat testis, germ cells and Sertoli cells during testicular maturation. Journal of Andrology 10, 145-151.

Swift, T.A. \& Dias, J.A. (1987) Stimulation of polyamine biosynthesis by follicle-stimulating hormone in serum-free cultures of Sertoli cells. Endocrinology $120,394-400$. 